\title{
No Correlation Between Nasopharyngeal Human Bocavirus 1 \\ Genome Load and mRNA Detection or Serology in
}

Adeno-/Tonsillectomy Patients

Ivaska, Lotta E.

2019-08-15

Ivaska, LE , Christensen, A, Waris , M , Puhakka , T , Vuorinen , T, Allander , T , Söderlund-Venermo , M \& Jartti , T 2019 , ' No Correlation Between Nasopharyngeal Human

Bocavirus 1 Genome Load and mRNA Detection or Serology in Adeno-/Tonsillectomy

Patients ' , Journal of Infectious Diseases , vol. 220 , no. 4 , pp. 589-593 . https://doi.org/10.1093/infdis/jiz166

http://hdl.handle.net/10138/321529

https://doi.org/10.1093/infdis/jiz166

unspecified

acceptedVersion

Downloaded from Helda, University of Helsinki institutional repository.

This is an electronic reprint of the original article.

This reprint may differ from the original in pagination and typographic detail.

Please cite the original version. 
TITLE PAGE

2 Brief Report

3 Title: No Correlation Between Nasopharyngeal Human Bocavirus 1 Genome Load and mRNA

4 Detection or Serology in Adeno-/tonsillectomy Patients

5

6 Running title: HBoV1 in Nasopharynx and Tonsils

7

8 Lotta E. Ivaska ${ }^{\mathrm{a}}$, Andreas Christensen ${ }^{\mathrm{b}, \mathrm{c}}$, Matti Waris ${ }^{\mathrm{d}}$, Tuomo Puhakka ${ }^{\mathrm{a}}$, Tytti Vuorinen ${ }^{\mathrm{d}}$, Tobias

$9 \quad$ Allander ${ }^{\mathrm{e}}$, Maria Söderlund-Venermo ${ }^{\mathrm{f}}$, Tuomas Jartti ${ }^{\mathrm{g}}$

10

11 a Department of Otorhinolaryngology - Head and Neck Surgery, Turku University Hospital and

12 University of Turku, 20521 Turku, Finland

$13{ }^{\mathrm{b}}$ Department of Laboratory Medicine, Norwegian University of Science and Technology, 7491

14 Trondheim, Norway

$15{ }^{\mathrm{c}}$ Department of Clinical Microbiology, St. Olavs Hospital, Trondheim University Hospital, 7030

16 Trondheim, Norway

$17{ }^{\mathrm{d}}$ Department of Virology and Clinical Virology, University of Turku and Turku University

18 Hospital, 20521 Turku, Finland

19 e Department of Clinical Microbiology, Karolinska University Hospital, 17176 Stockholm, Sweden

$20{ }^{\mathrm{f}}$ Department of Virology, University of Helsinki, 00014 Helsinki, Finland

$21{ }^{\mathrm{g}}$ Department of Paediatrics and Adolescent Medicine, Turku University Hospital and University of

22 Turku, 20521 Turku, Finland

23

24 Corresponding Author

25 Lotta E. Ivaska, MD, Fax: +358 2313 3525, Tel: +3582 3130000, E-mail: lesaar@utu.fi 
26 Alternate Corresponding Author

27 Tuomas Jartti, MD, PhD, Department of Pediatrics, Turku University Hospital, Fax: +358 2313

281460 Tel.: +358 407270 284, E-mail: tuomas.jartti@utu.fi

29

30 Word count: summary 39, abstract 100, body 1912

31

32 Summary

33 Relatively high loads of HBoV1 DNA can be detected in the nasopharynx of asymptomatic

34 subjects, which are negative for mRNA and/or serodiagnostic markers. HBoV1 DNA quantitative

35 PCR may have lower specificity than HBoV1 mRNA detection for diagnosing symptomatic 36 infection. 
Conflict of interest

Dr. Allander has a patent Human bocavirus and methods of diagnosis and treatment licensed to

40 Karolinska Institutet Innovations AB. Other authors report no potential conflicts of interest,

41 including relevant financial interests, activities, relationships and affiliations.

$43 \quad$ Funding

44 This work was supported by Turku University Hospital Foundation, Turku [to L.E.I.], Turku

45 University Foundation, Turku [to L.E.I.], the Sigrid Jusélius Foundation, Helsinki [to T.J.], and the 46 Life and Health Medical Association, Helsinki [M. S-V.], all in Finland.

48 Meetings

49 The content of this manuscript has been presented in form of a poster (abstract 729) in European

50 Society of Pediatric Otorhinolaryngology Conference in Stockholm June 2018.

52 Corresponding Author

53 Lotta E. Ivaska, MD, Department of Otorhinolaryngology - Head and Neck Surgery, Turku

54 University Hospital and University of Turku, 20521 Turku, Finland

55 Fax: +35823133525

56 Tel: +35823130000

57 E-mail: lesaar@utu.fi

58

59

60

61 
Human bocavirus 1 (HBoV1) can persist in nasopharynx and tonsils. Using HBoV1 serology,

64 reverse-transcription polymerase chain reaction (PCR) for detecting messenger RNA (mRNA) and

65 quantitative PCR for HBoV1 genome load count, we studied in what extent the HBoV1 DNA loads

66 in nasopharynx correlates with acute infection markers. Tonsillar tissue, nasopharyngeal aspirate

67 and serum were obtained from 188 elective adeno-/tonsillectomy patients. Relatively high loads of

68 HBoV1 DNA were detected in the nasopharynx of $14(7 \%)$ primarily asymptomatic subjects with

69 negative mRNA and/or serodiagnostic results. Quantitative HBoV1 DNA PCR may have lower

70 specificity than HBoV1 mRNA detection for diagnosing symptomatic infection.

71

72 Key words: bocavirus, parvovirus, nasopharynx, tonsil, serology, diagnosis, detection

73

74

75

76

77

78

79

80

81

82

83

84

85

86 


\section{BACKGROUND}

Human bocavirus (HBoV) was discovered in 2005 and belongs to the Parvoviridae family [1]. It is a non-enveloped single-stranded DNA virus causing mild to life-threatening respiratory tract infections in young children. HBoV1 is primarily transmitted by the respiratory route [1]. Three other human bocaviruses (HBoV2-4) have been discovered in stool and are considered enteric. $\mathrm{HBoV} 1$ is a frequent finding in young children suffering from lower respiratory tract illnesses such as bronchiolitis, wheezing, asthma and pneumonia [1,2]. The persistence of HBoV DNA in the airways and tonsils has been under investigation lately. In a recent study, HBoV DNA was found in tonsil squamous cell carcinoma tumors, prompting speculations of a possible causal association $[3,4]$. The virus is known to persist for weeks or months in the respiratory tract whereby a qualitative polymerase chain reaction (PCR) is insufficient as a diagnostic tool $[1,2,5,6]$. Microbiological diagnosis is often incorrectly based on a qualitative multiplex PCR. The most reliable diagnosis of acute $\mathrm{HBoV} 1$ infection is considered to be based on messenger RNA (mRNA) or a high HBoV1 DNA load in nasopharyngeal aspirate (NPA), DNA in serum, and serology $[1,2,5,7]$. HBoV1 DNA has been shown to also persist in adenoids and tonsils of children [8]. The aim of this study was to evaluate if high HBoV1 DNA loads occur in NPA or tonsils in adeno/tonsillectomy patients without acute HBoV1 infection, based on a documented lack of HBoV1 mRNA and/or IgM, the gold standards for diagnosis. We hypothesized that there is no active bocavirus replication in persistent $\mathrm{HBoV} 1$ detection.

\section{METHODS}

Study Population

Tonsil and nasopharyngeal samples were collected from 200 consecutive patients who underwent adeno-/tonsillectomy at the Satakunta Central Hospital, Pori, Finland, between April 2008 and March 2009. The inclusion criteria were tonsillectomy, adenotonsillectomy or adenotomy due to 
clinical indication and written informed approval from the study subject or his/her parents. Out of

113 the 200 enrolled patients, 12 yielded low-quality samples. In total, 188 patients with a median age

114 of 12 years (range 1-65) underwent elective adeno-/tonsillectomy ( $\mathrm{n}=143$ ) or sole adenotomy

$115(\mathrm{n}=45)$ and had sufficient and good quality biopsy samples for microbial and immunological studies

116 [9]. The main indications for tonsillectomy were recurrent tonsillitis in 43 (30\%) and tonsillar

117 hypertrophy in 48 (34\%) of 143 patients and for adenotonsillectomy, adenotonsillar hypertrophy in 11840 of $143(28 \%)$ patients, respectively [9]. Other indications ( $8 \%$ ) for adeno-/tonsillectomy were 119 e.g. throat abscess, recurrent fever, food remnants in tonsils and teeth braces. Indications for 120 adenotomy were hypertrophy in 17 (38\%) and recurrent otitis in $28(62 \%)$ of 45 patients. All the 121 study patients filled a standardized health questionnaire including respiratory symptoms 30 days 122 before and after the operation [9]. On the operation day $127(67 \%)$ had no respiratory tract 123 symptoms, $37(20 \%)$ reported mild respiratory symptoms and $24(13 \%)$ had no data.

126 Adeno-/tonsillectomy was performed by otorhinolaryngologists according to routine clinical 127 procedure. A part of the internal tonsillar tissue was instantly cut in 3-4 mm cubes, stored in 128 RNAlater, an RNA stabilization reagent (Qiagen, Hilden, Germany), incubated at $+2-8^{\circ} \mathrm{C}$ until the 129 next working day and finally stored at $-80^{\circ} \mathrm{C}[9]$. Nasopharyngeal aspirate samples were collected 130 using a standardized procedure. If the aspirate yield was small, the collection was repeated after 131 administration of $2 \mathrm{ml}$ physiologic saline. For viral analyses, a part of the tonsils and a 132 nasopharyngeal aspirate were stored in dry tubes at $-80{ }^{\circ} \mathrm{C}$ [9]. The first sample of the paired serum 133 samples was collected during the tonsillectomy anesthesia and the follow-up sample was taken in a 134 median of 58 days (range 36-104). 
137 The study protocols were approved by the Ethics Committee of the Satakunta Central Hospital and 138 by the Ethics Committee of the Hospital District of Southwest Finland.

Virus Diagnostics

141 Virus diagnostics of all NPA and tonsil samples was performed according to clinical routine using 142 PCR. Adenoid tissue samples were not analyzed. In-house real-time PCR assays were used to detect 143 HBoV1, rhinovirus, enterovirus, and respiratory syncytial virus as described previously [9]. Seeplex 144 RV12 ACE Detection (Seegene, Seoul, Korea) multiplex PCR assay was used for detection of 145 adenovirus, coronaviruses (229E/NL63 and OC43/HKU1), influenza A and B viruses, 146 metapneumovirus, parainfluenza virus types 1-3, respiratory syncytial virus group A and B, and 147 rhinovirus according to manufacturer's instructions. Quantitative PCR (qPCR) was used for 148 measuring the HBoV1 DNA load [10]. Serological tests for HBoV1-specific IgM and IgG were 149 performed for 122 patients [5,11]. Serology of the adenotomy patients $(n=45)$ was not analyzed. To 150 verify that the IgG results were $\mathrm{HBoV} 1$ specific, the serum samples were blocked with HBoV2 and 151 HBoV3 antigens. The mRNA expression levels of HBoV1 in NPA and tonsil samples were 152 analyzed by reverse-transcription PCR (RT-PCR) [7]. An RT-PCR detecting human beta-actin 153 mRNA was used as control for intactness of mRNA in the samples [12]. Virus PCR and qPCR were 154 done at the Department of Virology, University of Turku, Turku, Finland, and at the Department of 155 Clinical Microbiology, Karolinska University Hospital, Stockholm, Sweden. Serology was 156 analyzed at the Department of Virology, University of Helsinki and the RT-PCR at the Norwegian 157 University of Science and Technology, Trondheim, Norway.

RESULTS

160 HBoV1 DNA in NPA, tonsillar tissue, or in both samples, could be detected in 40 patients $(21 \%)$ 161 with a median age of 5 years (range 1-22). These patients did not have severe respiratory tract 
infection but 12 of 40 patients (30\%) reported one or more of the following: mild rhinitis, cough, symptoms of otitis, throat pain or upper airway obstruction symptoms on the operation day. In the sole adenotomy group 8 of 15 patients (53\%) and in the adeno-/tonsillectomy group 4 of 25 patients (16\%), respectively, reported symptoms (Tables 1-2).

Twenty-eight patients were positive for HBoV1 DNA in NPA only, 7 in tonsillar tissue only and 5 in both samples. Five sole adenotomy patients had high $\left(>10^{6}\right.$ copies $\left./ \mathrm{ml}\right)$ viral load in NPA using qPCR but were mRNA negative (Table 1). In the tonsillectomy group 9 patients had relatively high $\left(>10^{4}\right.$ copies $\left./ \mathrm{ml}\right)$ viral load in NPA but were mRNA negative and corresponding sera available were HBoV1 IgM-negative (Table 2). Only 1 patient gave a (barely) IgM-positive test result, but with a stable IgG absorbance in paired samples (Table 2). In all but three patients, the HBoV1 DNA

173 finding was accompanied with IgG positivity indicating a prior infection. These three HBoV1 174 DNA-positive but seronegative children had, however, prior HBoV2 immunity, which suggest that their HBoV1 IgG-negativity can be explained by an immunological phenomenon called original antigenic sin [13]. Furthermore, HBoV1-IgG levels did not increase in any of the 7 paired serum samples of HBoV1 DNA-positive patients (Table 2). All 29 NPAs and 8 tonsils analyzed were

178 HBoV1-mRNA negative (Tables 1-2). Eight NPA samples with HBoV1 DNA loads $>10^{4}$ were tested with the beta actin-mRNA PCR, all with strongly positive results.

\section{DISCUSSION}

182 Our study confirms that HBoV1 can be found in the respiratory tract of patients with chronic and 183 recurrent adenotonsillar disease. Quite a high prevalence (21\%) of HBoV1 DNA in tonsils and/or 184 NPA of elective adeno-/tonsillectomy patients was detected which agrees with earlier studies [8]. An even higher prevalence (43\%) has been discovered in mainly asymptomatic subjects but the patients were small children (median age of 23 months) undergoing elective adeno-/tonsillectomy 
and/or myringotomy [14]. We also found relatively high $\left(>10^{4}\right.$ copies $\left./ \mathrm{ml}\right)$ or high $\left(>10^{6}\right.$ copies $\left./ \mathrm{ml}\right)$ HBoV1 DNA loads in nasopharynx of $13 \%$ and $3 \%$ our study patients, respectively. However, the high DNA loads were not accompanied by positive HBoV1 mRNA or serological responses. Our results supported the study hypothesis that HBoV1 was not actively transcribing in persistent 191 infection.

193 The most common laboratory diagnostic method for respiratory infections is qualitative PCR, 194 despite the fact that HBoV1 DNA can, due to prolonged presence or intermittent shedding, be 195 detected in the nasopharynx for months after a symptomatic respiratory infection $[1,6,15]$. Previous 196 studies have suggested that the DNA amount decreases over time and that high DNA loads $\left(>10^{4}\right.$ to $19710^{6}$ copies $/ \mathrm{ml}$, depending on the study) would be a sign of acute bocavirus infection $[2,5,7,15]$. To 198 define one specific threshold for high viral load is very demanding due to the various test methods, 199 the type and quality of the specimens, and the time of collection. In our study we found high loads $200\left(>10^{6}\right.$ copies $\left./ \mathrm{ml}\right)$ of HBoV1 DNA particularly in adenotomy patients of which 3 were asymptomatic 201 and 2 had mild respiratory tract symptoms. Only 1 adeno-/tonsillectomy patient with relatively high 202 viral load $\left(>10^{4}\right.$ copies $\left./ \mathrm{ml}\right)$ reported symptoms.

204 In addition, mRNA of HBoV1 has been used as a marker of viral activity: HBoV1 mRNA can be 205 detected in NPA of patients with symptomatic respiratory tract infection but not in asymptomatic 206 controls [2,7]. It is known that HBoV1 DNA is stored in adenotonsillar tissue [8]. We wanted to 207 investigate the viral activity in tonsils. None of the tonsils showed HBoV1 mRNA regardless of the 208 HBoV-DNA load. Furthermore, all NPAs were also mRNA negative, in line with earlier studies of 209 non-acute HBoV1 infections[7,8]. Conversely, in previous studies, the detection of HBoV1 mRNA 210 in symptomatic patients was associated with high HBoV1 DNA loads [2,7]. In our elective adeno211 /tonsillectomy patients, relatively high loads of HBoV1 DNA in the respiratory tract were not 
associated with concomitant viral replication demonstrated by the lack of mRNA detection. Our data suggests that HBoV1 DNA or its high load by qPCR are less specific markers for acute

214 HBoV1 infection than mRNA, at least in adenotonsillar surgery subjects. In this respect, our data 215 support using HBoV1 mRNA detection as a more reliable method for diagnosing acute infection as 216 suggested previously $[2,7,8]$.

218 Serological results were in line with the clinical findings and did not support acute HBoV1 219 infection in any patients. Since most patients studied by serology were $\geq 5$ years of age, they most 220 likely have already experienced primary bocavirus infection. The HBoV1 DNA finding in the 221 respiratory tract was accompanied by $\operatorname{IgG}$ positivity in $18 / 25$ cases (no sera available $n=4$ ), of 222 which 17 were IgM negative, indicating past infections. The one barely IgM-positive patient with 223 HBoV1 DNA in tonsils, showed an already high and stable IgG in paired samples, indicating a 224 recent but non-acute infection. In two earlier studies among wheezing children, there has been an 225 association of high $\left(>10^{4}\right.$ or $>10^{6}$ copies/ml $)$ HBoV1 DNA load with diagnostic serology [2,5]. 226 This association could not be found in the current study of primarily asymptomatic tonsillectomy 227 patients due to lack of acute infections. We show that persisting HBoV1 DNA can be of relatively 228 high loads also in non-acute infections.

This study provides new information about HBoV1 DNA positivity without clinical 231 illness/manifestation and also confirms earlier results of HBoV1 diagnosis [2,5-7,15]. Earlier 232 studies have focused on young children with respiratory tract infection $[5,7,14,15]$ whereas our 233 study had slightly older and mainly asymptomatic adeno-/tonsillectomy patients. A major 234 limitation of the current study is that the data set was not complete: 8 of the $45(18 \%)$ HBoV1 PCRpositive NPA or tonsillar tissue samples were not analyzed by mRNA RT-PCR. Another limitation of this study is the low number of paired serum samples. Serum samples were not available at the 
enrollment $(\mathrm{n}=4)$, at the follow-up visit $(\mathrm{n}=10)$ or both samples $(\mathrm{n}=4)$. Serology of the adenotomy group was not analyzed. However, this is still the largest study on subjects without acute respiratory symptoms that compares different diagnostic methods for HBoV1 infection.

241 In conclusion, we did not find a correlation between HBoV1 genome load and mRNA detection or

242 serology in adeno-/tonsillectomy patients. Our findings support the use of HBoV1 mRNA detection 243 and serology as more specific diagnostic tools to identify acute bocavirus infection.

NOTES

$247 \quad$ Funding

248 This work was supported by the Turku University Hospital Foundation, Turku [to L.E.I.], the Turku 249 University Foundation, Turku [L.E.I.], the Sigrid Jusélius Foundation, Helsinki [to T.J.], and the 250 Life and Health Medical Association, Helsinki [to M. S-V.], all in Finland.

252 Acknowledgments

253 We acknowledge Lea Hedman and Heidi Jokinen for technical help.

255 Potential conflicts of interest

256 Dr. Allander has a patent Human bocavirus and methods of diagnosis and treatment licensed to 257 Karolinska Institutet Innovations AB. Other authors: no reported conflicts. 
261 1. Qiu J, Söderlund-Venermo M, Young NS. Human Parvoviruses. Clin Microbiol Rev 2017; $262 \quad 30: 43-113$.

263 2. Xu M, Arku B, Jartti T, et al. Comparative Diagnosis of Human Bocavirus 1 Respiratory 264 Infection With Messenger RNA Reverse-Transcription Polymerase Chain Reaction (PCR), 265 DNA Quantitative PCR, and Serology. J Infect Dis 2017; 215:1551-7.

266 3. Höpken M, Förster I, Maune S, Brockmann M, Schildgen O, Schildgen V. Association of the 267 Human Bocavirus With Tonsil Squamous Cell Carcinomas. Front Microbiol 2018; 9:2450.

268 4. Schildgen V, Pieper M, Khalfaoui S, Arnold WH, Schildgen O. Human Bocavirus Infection of Permanent Cells Differentiated to Air-Liquid Interface Cultures Activates Transcription of Pathways Involved in Tumorigenesis. Cancers 2018; 10:410.

271 5. Söderlund-Venermo M, Lahtinen A, Jartti T, et al. Clinical assessment and improved diagnosis of bocavirus-induced wheezing in children, Finland. Emerg Infect Dis 2009; $15: 1423-30$.

6. Windisch W, Pieper M, Ziemele I, et al. Latent infection of human bocavirus accompanied by flare of chronic cough, fatigue and episodes of viral replication in an immunocompetent adult patient, Cologne, Germany. JMM case reports 2016; 3:e005052.

277 7. Christensen A, Døllner H, Skanke LH, Krokstad S, Moe N, Nordbø SA. Detection of Spliced mRNA from Human Bocavirus 1 in Clinical Samples from Children with Respiratory Tract Infections. Emerg Infect Dis 2013; 19:574-80.

280 8. Proenca-Modena JL, Paula FE, Buzatto GP, et al. Hypertrophic adenoid is a major infection 281 site of human bocavirus 1. J Clin Microbiol 2014; 52:3030-7.

282 9. Jartti T, Palomares O, Waris M, et al. Distinct regulation of tonsillar immune response in virus infection. Allergy 2014; 69:658-67.

284 10. Tiveljung-Lindell A, Rotzén-Ostlund M, Gupta S, et al. Development and implementation of 
a molecular diagnostic platform for daily rapid detection of 15 respiratory viruses. J Med Virol 2009; 81:167-75.

287 11. Kantola K, Hedman L, Arthur J, et al. Seroepidemiology of human bocaviruses 1-4. J Infect Dis 2011; 204:1403-12.

289 12. Nyström K, Biller M, Grahn A, Lindh M, Larson G, Olofsson S. Real time PCR for monitoring regulation of host gene expression in herpes simplex virus type 1-infected human diploid cells. J Virol Methods 2004; 118:83-94.

292 13. Kantola K, Hedman L, Tanner L, et al. B-Cell Responses to Human Bocaviruses 1-4: New 293 Insights from a Childhood Follow-Up Study. PLoS One 2015; 10:e0139096.

294 14. Longtin J, Bastien M, Gilca R, et al. Human Bocavirus Infections in Hospitalized Children and Adults. Emerg Infect Dis 2008; 14:217-21.

296 15. Christensen A, Nordbø SA, Krokstad S, Gro A, Rognlien W, Døllner H. Human bocavirus in children: Mono-detection, high viral load and viraemia are associated with respiratory tract infection. J Clin Virol 2010; 49:158-62. 
Table 1. Adenotomy patients with HBoV1 DNA-positive NPA samples

\begin{tabular}{|c|c|c|c|c|c|c|}
\hline $\begin{array}{l}\text { Case } \\
\text { no. }\end{array}$ & $\begin{array}{l}\text { Age } \\
\text { (y) }\end{array}$ & $\begin{array}{l}\text { Adenotomy } \\
\text { indication }\end{array}$ & $\begin{array}{l}\text { Symptoms }{ }^{\mathrm{a}} \text { on } \\
\text { the operation } \\
\text { day }\end{array}$ & $\begin{array}{l}\text { HBoV1 NPA } \\
\text { PCR result }\end{array}$ & $\begin{array}{l}\text { HBoV1 DNA load } \\
(\mathrm{cp} / \mathrm{ml}) \text { in NPA }\end{array}$ & $\begin{array}{l}\text { mRNA } \\
\text { NPA }\end{array}$ \\
\hline B013 & 4 & ROM & yes & pos & 128800 & neg \\
\hline B038 & 3 & ROM & no & pos & 123800 & neg \\
\hline B061 & 2 & ROM & no & pos & 550000 & neg \\
\hline B064 & 2 & ROM & no & pos & 176800 & neg \\
\hline B066 & 3 & ROM & yes & pos & 141200 & neg \\
\hline B073 & 3 & ROM & no & pos & 100396800 & neg \\
\hline B074 & 5 & ROM & no & pos & 36200 & neg \\
\hline B087 & 3 & ROM & yes & pos & 28269400 & neg \\
\hline B100 & 6 & $\mathrm{AH}$ & yes & pos & 19708800 & neg \\
\hline B122 & 8 & $\mathrm{AH}$ & yes & pos & 358200 & neg \\
\hline B126 & 4 & $\mathrm{AH}$ & yes & pos & 16800 & neg \\
\hline B129 & 2 & ROM & yes & pos & 117400 & neg \\
\hline B182 & 2 & ROM & no & pos & 20537600 & neg \\
\hline B184 & 1 & ROM & no & pos & 2227000 & neg \\
\hline B194 & 2 & ROM & yes & pos & 91600 & neg \\
\hline
\end{tabular}

302 Abbreviations: y, years; ROM, recurrent otitis media; AH, adenoid hypertrophy; NPA,

303 nasopharyngeal aspirate; cp, copies. ${ }^{a}$ One or more of the following: mild rhinitis, cough, symptoms

304 of otitis, throat pain, upper airway obstruction symptoms. 
305 Table 2. Adeno-/tonsillectomy patients with HBoV1 DNA-positive NPA and/or tonsillar tissue

306 samples

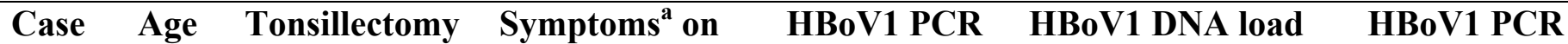

no. (y) indication the operation result, NPA $(\mathrm{cp} / \mathrm{ml}), \mathrm{NPA} \quad$ result, tonsils day

\begin{tabular}{|c|c|c|c|c|c|c|}
\hline B004 & 6 & $\mathrm{ATH}$ & no & pos & NA & neg \\
\hline B008 & 6 & $\mathrm{ATH}$ & no & pos & 400 & neg \\
\hline B015 & 8 & $\mathrm{ATH}$ & no & pos & 500 & neg \\
\hline B021 & 8 & $\mathrm{ATH}$ & no & pos & 4400 & neg \\
\hline B028 & 16 & $\mathrm{RT}, \mathrm{TH}$ & no & pos & NA & neg \\
\hline B051 & 7 & $\mathrm{ATH}$ & no & pos & 133200 & neg \\
\hline B069 & 8 & RT & no & pos & 600 & neg \\
\hline B113 & 12 & ATH & NA & pos & 119200 & neg \\
\hline B130 & 5 & ROM, ATH & NA & pos & 30400 & neg \\
\hline B160 & 7 & ATH & yes & pos & 4000 & neg \\
\hline B162 & 6 & ATH & no & pos & 210600 & neg \\
\hline B169 & 7 & RT & no & pos & 7600 & neg \\
\hline B185 & 7 & $\mathrm{ATH}$ & NA & pos & 8600 & neg \\
\hline B018 & 22 & RT & yes & neg & 0 & pos \\
\hline B019 & 5 & ROM, RT, TH & no & neg & 0 & pos \\
\hline B036 & 4 & ATH & NA & neg & 0 & pos \\
\hline B135 & 3 & ATH & no & neg & 0 & pos \\
\hline B193 & 2 & ATH & no & neg & 0 & pos \\
\hline B195 & 9 & ATH & no & neg & 0 & pos \\
\hline
\end{tabular}


B198 3 ROM, ATH, yes $\quad$ neg $\quad 0 \quad$ pos recurrent fever

$\begin{array}{llllcll}\text { B056 } & 5 & \text { ATH } & \text { yes } & \text { pos } & 307800 & \text { pos } \\ \text { B082 } & 4 & \text { ATH } & \text { no } & \text { pos } & 32200 & \text { pos } \\ \text { B106 } & 4 & \text { ATH } & \text { no } & \text { pos } & 220800 & \text { pos } \\ \text { B150 } & 5 & \text { RT, ATH } & \text { NA } & \text { pos } & 92400 & \text { pos } \\ \text { B197 } & 3 & \text { ATH } & \text { no } & \text { pos } & 202600 & \text { pos }\end{array}$

309 Abbreviations: y, years; ATH, adenotonsillar hypertrophy; TH, tonsillar hypertrophy, ROM, 310 recurrent otitis media; RT, recurrent tonsillitis; NPA, nasopharyngeal aspirate; cp, copies; NA, not 311 available; abs., absorbance (cutoff $\geq 0.131$ ).

$312{ }^{\text {a }}$ One or more of the following: mild rhinitis, cough, symptoms of otitis, throat pain, upper airway 313 obstruction symptoms.

$314{ }^{\mathrm{b}}$ Paired serum samples; no increase in IgG.

$315 \quad{ }^{c}$ No acute-phase serum sample available.

$316{ }^{\mathrm{d}} \mathrm{HBoV} 2 \mathrm{IgG}$ positive; may influence induction of HBoV1 IgG through original antigenic sin [13].

$317{ }^{\mathrm{e}}$ Very low absorbance level; 0,147. Together with a stable IgG level in paired samples, the 318 interpretation is recent but non-acute HBoV1 infection. 